\title{
ON SUPPOSED DISCONTINUITIES IN THE MANTLE OF THE EARTH
}

\author{
By B. Gutenberg and C. F. Richter
}

It has always been an interesting question whether there are discontinuities at depths between 40 and 1,200 kilometers, which are the upper and the lower limits of the true mantle of the earth. Some geophysicists have suspected a layer at the depth of 120 kilometers corresponding to the depth of isostatic equilibrium, but it is very improbable that a definite surface of this kind exists. There can not be a specific depth at which stresses are equalized by flowing movements, for the strength which resists these movements cannot fall to zero suddenly, but must do so over a rather wide range of depth.

Chapman suggests another discontinuity at a depth of 200 to 300 kilometers corresponding to a sudden increase of the electric conductivity. Between 300 and 400 kilometers Wadati (1) found a maximum of frequency for earthquakes having deep foci. This fact might be interpreted in favor of a discontinuity. Finding a rather rapid decrease in amplitude of the $P$-waves over the range of distances between 500 and 1,600 kilometers, followed by a sudden increase, Gutenberg (2) concluded that there is a region at depths from 60 to 70 kilometers where the wave-velocities decrease very slightly with increasing depth. Finally $H$. Jeffreys (3) found a sudden change of the direction of the travel-time curve for $P$-waves corresponding to rays having their deepest point at these depths. In addition to this he suspected a discontinuity at a depth of 270 kilometers indicated by irregularity of the travel-time curve at distances in the neighborhood of 20 degrees. $^{1}$

The records of the Mexican shocks of January 2, 15, and 17, 1931, at Pasadena with its auxiliary stations in southern California, and also the records at Berkeley and Lick Observatory afford an opportunity to work with seismograms of shocks from distances between $10^{\circ}$ and $30^{\circ}$. Using the preliminary reports of the United States Coast and Geodetic Survey and of the Jesuit Seismological Association, we have adopted the following co-ordinates of the epicenters:

${ }^{1}$ In a recent letter Dr. Jeffreys informs us that he no longer considers this probable. 


\begin{tabular}{|c|c|c|}
\hline Date & Latitude & Longitude \\
\hline 1931 January 2 & $18^{\circ} \mathrm{N}$. & $108^{\circ} \mathrm{V}$ \\
\hline January 15 & $15.5 \mathrm{~N}$. & $96.5 \mathrm{~V}$ \\
\hline January 17 & $25.5 \mathrm{~N}$. & $110.5 \mathrm{~V}$ \\
\hline
\end{tabular}

Even if these data are in error by several degrees, the differences between the distances of the stations used will not be very much affected, as all these stations are situated in nearly the same azimuth from these epicenters. Thus it will be possible to find $d t / d \Delta$ ( $t=$ time, $\Delta=$ epicentral distance) with considerable accuracy and to determine approximately the relation between the amplitudes and the distance. The readings of the first motion at the several stations are given in Table I and plotted against the distance in Figure 1, and the values of $d t / d \Delta$ as derived from these are given in Table II (p. 218).

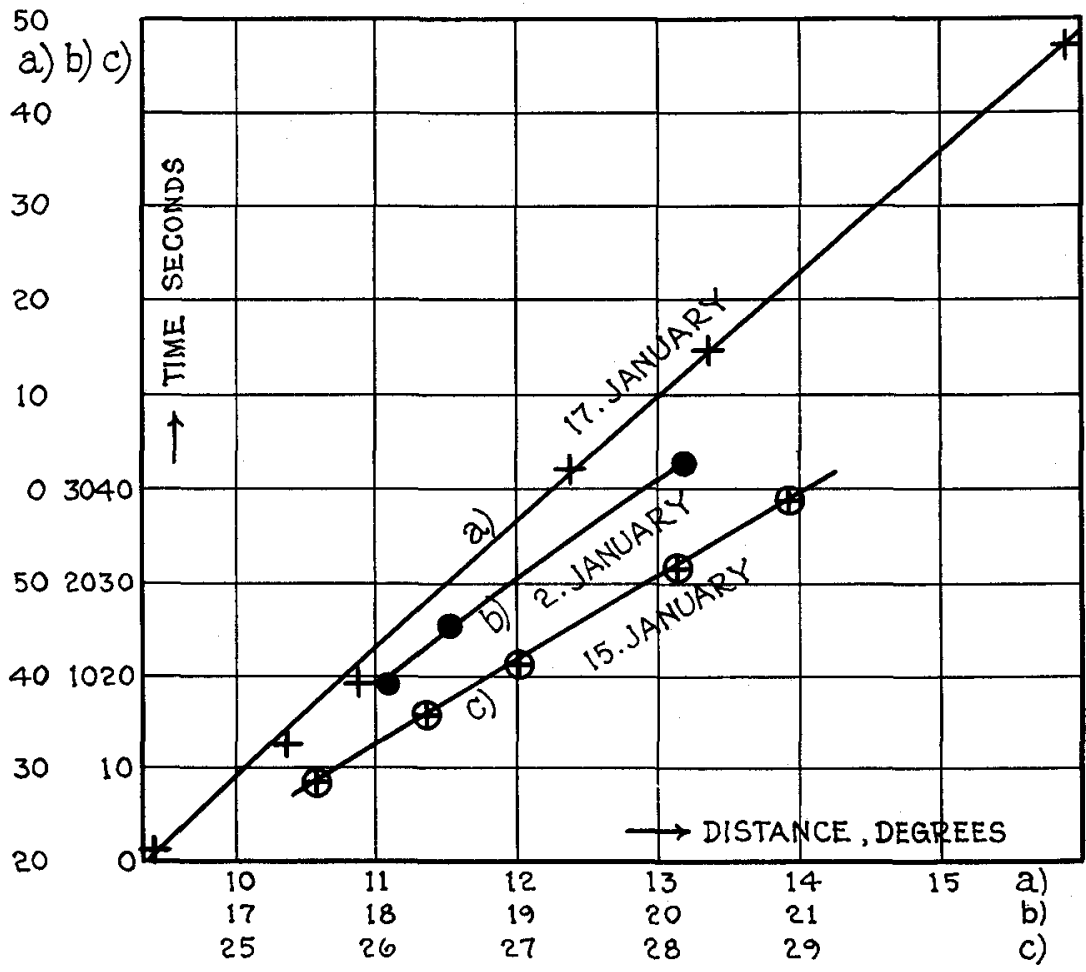

FIG. 1 


\section{TABLE I}

\begin{tabular}{|c|c|c|c|c|c|c|c|}
\hline \multirow{2}{*}{\multicolumn{2}{|c|}{ Station }} & \multicolumn{2}{|c|}{ January $2,9^{\text {h }}$} & \multicolumn{2}{|c|}{ January $15,1^{\mathrm{h}}$} & \multicolumn{2}{|c|}{ January $17,2^{\text {h }}$} \\
\hline & & $\Delta$ & $t$ & $\Delta$ & $t$ & $\Delta$ & $t$ \\
\hline La Jolla & & $\cdots$ & & $25^{\circ} 35^{\prime}$ & $56^{\mathrm{m}} 08 \mathrm{~s} 7$ & $9^{\circ} 25^{\prime}$ & $25 \mathrm{~m} 21 \mathrm{~s}$ \\
\hline Riverside & & $18^{\circ} 04^{\prime}$ & $53^{\mathrm{m}} 09 \mathrm{~s} 2$ & 2622 & 15.8 & 1023 & 32.8 \\
\hline Pasadena & & 1831 & 15.1 & 2659 & 20.8 & $10 \cdot 53$ & 39 \\
\hline Haiwee & & 2010 & 32.5 & 28. 08 & 31.6 & 1223 & $\begin{array}{ll}53 & 02.3\end{array}$ \\
\hline Tinemaha & & $\ldots \ldots$ & $\ldots$ & 2856 & 38.9 & 1321 & 14.8 \\
\hline Berkeley & $\ldots \ldots \ldots \ldots$ & $\ldots \ldots$ & $\ldots$ & $\ldots \ldots$ & $\ldots$ & 1552 & 47 \\
\hline
\end{tabular}

\section{TABLE II}

Distance $10^{\circ} \quad 12^{\circ} \quad 14^{\circ} \quad 16^{\circ} \quad 18^{\circ} \quad 20^{\circ} \quad 22^{\circ} \quad 24^{\circ} \quad 26^{\circ}$

$d t / d \Delta \ldots \ldots 13.6 \quad 13.6 \quad 13.5 \quad 12.6 \quad 11.0 \quad 10.2 \quad 9.6 \quad 9.3 \quad 9.1$ Seconds per dègree

$d \Delta / d t \ldots \ldots \quad 8.2 \quad 8.2 \quad 8.2 \quad 8.8 \quad 10.1 \quad 10.9 \quad 11.6 \quad 11.912 .2$ Kilometers per second

Every marked change in $d t / d \Delta$ must be connected with a change in the amplitudes. There is no suspicion of irregularities at distances between twenty-five and twenty-nine degrees. Using the seismograms of our stations for the shock of January $15 \mathrm{th}$, in which the distances of our stations were within these limits, we find indeed no marked changes of amplitudes from station to station. It is very fortunate that all our stations have the same kind of instruments, name'y Wood-Anderson torsion seismometers with free periods of 0.8 of a second and a static magnification of 2,800 . As the periods of the waves are nearly the same at all stations we can compare the recorded amplitudes at the several stations with an error not larger than that introduced by the usual calculation of the so-called "true amplitudes." At Tinemaha alone the amplitudes are slightly larger than elsewhere. This may be an effect of the ground or may be instrumental in origin.

Similar results were obtained for the shock of January $2 \mathrm{~d}$, as Table III shows. On January 17 th the amplitudes of the $P$-waves in general were very small. Slightly larger amplitudes were found at Haiwee and Tinemaha at distances of $12 \mathrm{I} / 2$ and $13 \mathrm{I} / 2$ degrees. The seismograms, Figure 2, show that $P$ begins with a very small motion at the nearest stations and that at distances beyond $121 / 2$ degrees the amplitudes of the $P$-waves are considerably larger.

Similar results were found for the $S$-waves. The seismograms at the smaller distances show no recognizable $S$-phases. At distances between $12^{\circ}$ and $18^{\circ}$ the amplitudes of the $S$-waves increase slowly, but even at these distances the beginning of this phase is usually not well marked. Beyond $20^{\circ} S$ is rather definite. Thus the results obtained 


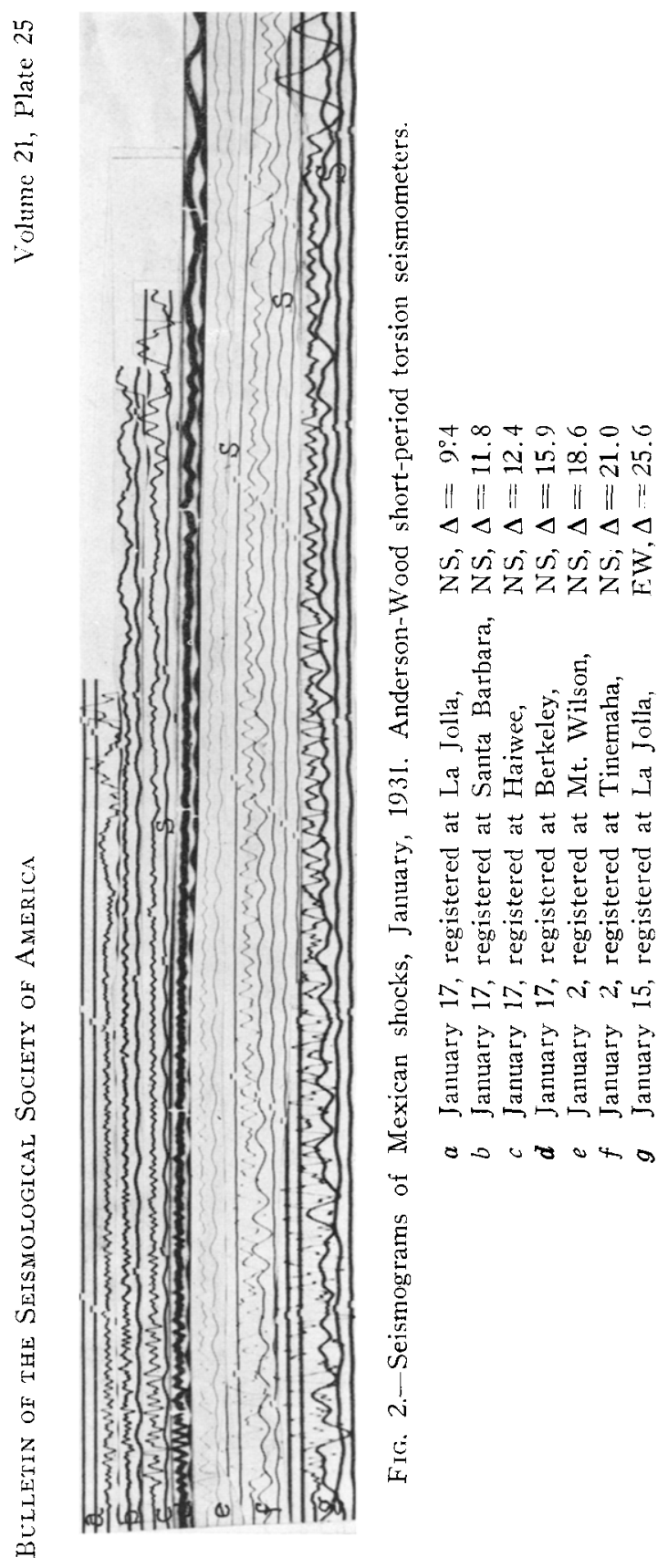


TABLE III

Horizontal Amplitudes of P-Waves, Measured on the Seismograms, in Millimeters

\begin{tabular}{|c|c|c|c|c|c|c|c|c|c|}
\hline \multirow[t]{2}{*}{ Station } & \multicolumn{3}{|c|}{ January 17} & \multicolumn{3}{|c|}{ January 2} & \multicolumn{3}{|c|}{ January 15} \\
\hline & $\Delta$ & $e^{*}$ & $m$ & $\Delta$ & $e$ & $m$ & $\Delta$ & $e$ & $\bar{m}$ \\
\hline La Jolla .... & $9^{\circ}$ & $3 / 4$ & 2 & $\cdots$ & $\ldots$ & $\ldots$ & $26^{\circ}$ & $11 / 2$ & 8 \\
\hline Riverside ... & 10 & $I / 2$ & 1 & $18^{\circ}$ & $21 / 2$ & 9 & 26 & $1 / / 2$ & 6 \\
\hline Pasadena ........ & 11 & $1 / 2$ & $11 / 2$ & 19 & $21 / 2$ & 8 & 27 & $11 / 2$ & 6 \\
\hline Mt. Wilson ...... & . & $\ldots$ & $\ldots$ & 19 & $11 / 2$ & 7 & $\ldots$ & $\ldots$ & . \\
\hline Santa Barbara .... & 12 & $I / 2$ & 2 & 19 & $11 / 2$ & $31 / 2$ & $\ldots$ & $\cdots$ & . \\
\hline Haiwee ........ & 12 & 1 & 4 & 20 & $3 / 4$ & 3 & 28 & $3 / 4$ & 5 \\
\hline Tinemaha ...... & 13 & 2 & 10 & 21 & $1 \mathrm{I} / 2$ & 10 & 29 & $1 \mathrm{I} / 2$ & 12 \\
\hline
\end{tabular}

* $e$ refers to the first motion, $m$ to the maximum.

from the $P$ - and $S$-waves correspond very we'l. There is no sign in either case of a sudden change at larger distances than $18^{\circ} ; d t / d \Delta$ also shows no irregular change at distances over $19^{\circ}$. Between $13^{\circ}$ and $19^{\circ}$ there is no sign of any abrupt change, but our data are not sufficient for positive conclusions. These observations make it very improbable that there exists a discontinuity at any level where rays emerging at such distances have their deepest point. The irregularities of $d t / d \Delta$ found by Jeffreys for $S$-waves at a distance of $20^{\circ}$ may be explained by the indefinite nature of the $S$-waves at distances between $10^{\circ}$ and $20^{\circ}$, in which case we found no marked phases between the beginning of the seismogram and the long waves.

From the values $d t / \Delta$ we can calculate $i$, the angle of incidence:

$$
\sin i=v_{\mathrm{c}} \frac{d \Delta}{d t} \text {. }
$$

$v_{0}$ was taken as 5.6 kilometers per second, which is representative of the va'ues 5.5 and 5.55 found by $\mathrm{H}$. O. Wood and C. F. Richter from blasts and a small group of earthquakes in southern California (4) and 5.57 found by B. Gutenberg ( 5 ) as a mean value from sixteen earthquakes in southern California. For purposes of approximate calculation we may assume the values found by Gutenberg (5) for California. ${ }^{2} \mathrm{We}$

2 The values found by Gutenberg (5) are:

\begin{tabular}{|c|c|c|c|}
\hline $\begin{array}{c}\text { Depth } \\
\text { km }\end{array}$ & & $\begin{array}{c}\text { Velocity of } P \\
\mathrm{~km} / \mathrm{sec} .\end{array}$ & $\begin{array}{c}\text { Velocity of } S \\
\mathrm{~km} / \mathrm{sec} .\end{array}$ \\
\hline $0-14$ & & $5.54-5.59$ & 3.23 \\
\hline $14-25$ & .. & 6.05 & 3.39 \\
\hline $25-31$ & $\cdots \ldots \ldots$ & 6.83 & 3.66 \\
\hline $31-39$ & 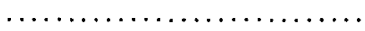 & 7.6 & 4.24 \\
\hline$>39$ & $\ldots \ldots \ldots \ldots \ldots$ & 7.94 & 4.45 \\
\hline
\end{tabular}


can now calculate $\sin i^{\prime}$, in which $i^{\prime}$ is the angle of incidence at the depth of 40 kilometers in the third layer, as a function of the distance measured at the level of the second discontinuity. An error in these numerical values will not affect the results very much. From this new curve for $\sin i^{\prime}$ as a function of the distance we can calculate the velocity as a function of the depth, using the method of Bateman, Herglotz, and Wiechert. The results are given in Figure 3. The broken line of

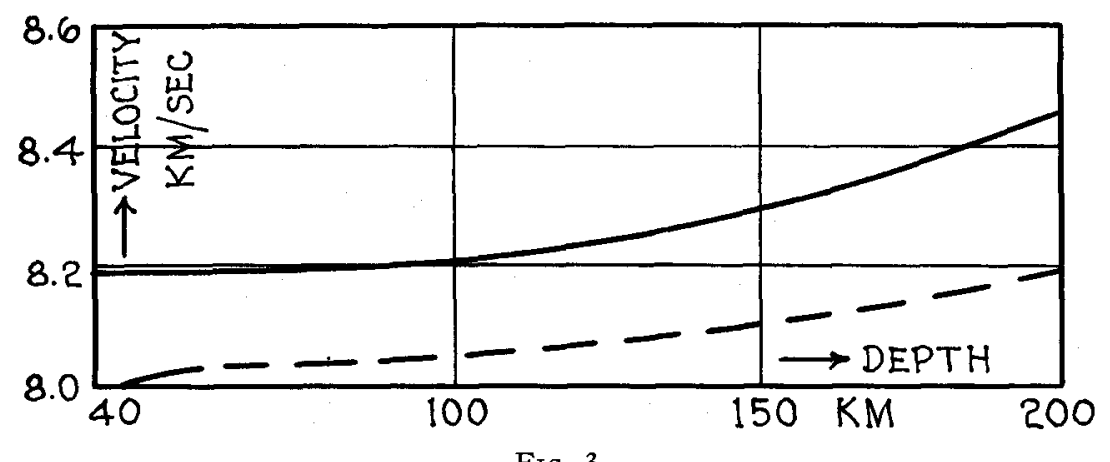

FIG. 3

this figure corresponds to values found for Europe and Japan by Gutenberg, the full line to our new results for California. The difference of the two curves is within the limits of error, though a velocity of 7.8 to 8.1 kilometers per second has been found in many cases for $P_{n}$-waves in Europe and Japan, and a mean value of 7.94 kilometers per second by Gutenberg for the California earthquakes mentioned above.

In Europe and in Japan a very sharp limit had been found between seismograms with small $P$-waves from distances less than $15^{\circ}$ and those with large $P$-waves from greater distances. In this connection it should be noted that all the instruments then used wrote on smoked paper, in which case small amplitudes are proportionally more reduced than large ones, since both are decreased by the same amount. In our case we can only say that the increase in amplitudes in $P$ must occur between $121 / 2$ and 18 degrees. The large amplitudes at Tinemaha on January 17 th (distance $13^{\circ}$ ) may be the beginning of this increase. Thus there is no reason to suppose a sudden change of $i^{\prime}$ with distance. Even if such a sudden change were assumed, the result would not be very different, as is shown by the broken line of Figure 3, which was calculated with such an assumption. In this case the "sudden" change of velocity with 
depth can only be seen from a curve on a very large scale. If the velocity decreases suddenly with depth, there must be similar effects to those found for the $P$-waves encountering the boundary of the core. For this reason a search was made for complications in the $P$-phase. As a matter of fact we found in all three shocks and at nearly all stations at least two different phases of which the time intervals and the ratios of the amplitudes were measured. The results are given in Table IV.

\section{TABLE IV}

Time Intervals and Ratio of Amplitudes (in Parentheses) of $P$-Waves

\begin{tabular}{|c|c|c|c|c|c|c|c|c|c|c|c|}
\hline Stations & $\Delta$ & \multicolumn{2}{|c|}{ January 17} & $\Delta$ & \multicolumn{4}{|c|}{ January 2} & $\Delta$ & \multicolumn{2}{|c|}{ January 15} \\
\hline La Jolla ........ & $9^{\circ}$ & 3 & $9\left(\begin{array}{ll}5 & 3\end{array}\right)$ & $\cdots$ & & $\cdots$ & $?$ & & $26^{\circ}$ & 5 & $15(42)$ \\
\hline Riverside ... & 10 & 5 & (?) & $18^{\circ}$ & 4 & 3 & ( 4 & 4) & 26 & 4 & $9(84)$ \\
\hline Pasadena .. & 11 & 3 & $12(84)$ & 19 & 4 & $J$ & & 5) & 27 & $?$ & (?) \\
\hline Mount Wilsor & $?$ & ? & 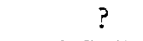 & 19 & 4 & 4 & $\left(4 \frac{1}{2}\right.$ & 3) & $?$ & $?$ & $?$ \\
\hline Santa Barbara.. & 12 & 5 & $11(52)$ & 19 & 5 & $21 / 2$ & $(3$ & ?) & $?$ & $?$ & $?$ \\
\hline ee $\ldots \ldots \ldots$. & 12 & 5 & $10(148)$ & 20 & $21 / 2$ & $?$ & $(5$ & ?) & 28 & 5 & $12(42)$ \\
\hline Tin & 13 & 3 & $7\left(\begin{array}{ll}15 & 3\end{array}\right)$ & 21 & 5 & $?$ & $(10$ & ?) & 29 & $31 / 2$ & $7(63)$ \\
\hline Lic & 15 & 4 & $10(53)$ & $?$ & ? & & $?$ & & $?$ & $?$ & $?$ \\
\hline Berkeley & 16 & $31 / 2$ & $10(43)$ & ? & ? & & $?$ & & $?$ & $?$ & ? \\
\hline
\end{tabular}

There is only one time interval which occurs fairly frequently. This is in the neighborhood of four seconds and may possibly increase slightly with distance. On the other hand there is no marked change in the ratio of the amplitudes of the second wave to the amplitudes of the first waves. It is usually about $4: 1$. Thus Table IV gives no definite conclusion as to a sudden change of velocity with depth. We can only conclude that the velocity of $P$-waves does not increase or may even decrease slightly at depths between 40 and 100 kilometers and that a rather rapid increase of velocity begins at a depth of more than 100 kilometers.

It would be very interesting to investigate the $S$-waves in a similar way, but as stated above, the seismograms at our disposal show no marked $S$-waves at distances between $9^{\circ}$ and $18^{\circ}$. The curve $d t / d \Delta$ for $S$-waves therefore could not be constructed. In working over the seismograms one has the impression that the $S$-wave is still more affected by the conditions at depths between 40 and 100 kilometers than the $P$-wave, as in most of our seismograms from small distances there is no trace of $S$-waves, even on the records of the long-period instru- 
ments. This suggests that the normal increase with depth of the modulus of rigidity is modified more than that of the bulk-modulus. It seems not improbable that at these depths the temperature of the material is near its melting-point. As Daly has pointed out (6), the density and the elastic constants of a rock melting at such a depth are decreased in about the same ratio, and therefore the wave-velocities are only slightly changed. At greater depths the increasing pressure causes an increase of both elastic moduli and consequently of the wave-velocities. From our data it is not possible to determine at what depth between 40 and 100 kilometers the suspected transition from the crystalline to the glassy state takes place, but it is very probable that in California the depth will be found the same $(60-70 \mathrm{~km})$ as in other countries (2).

\section{SUMMARY}

Investigations of the Mexican shocks of January 2, 15, and 17, 1931, as recorded at stations in California have shown that the travel-time curve of the $P$-waves at distances between $9^{\circ}$ and $15^{\circ}$ is nearly a straight line. At these distances the amplitudes of the $P$-waves are very small, as is to be expected from theory. At greater distances $d t / d \Delta$ decreases, and the amplitudes are larger. The data are not sufficient to decide whether the changes are abrupt or not. No $S$-waves could be found between $9^{\circ}$ and $15^{\circ}$. The calculated velocities of the $P$-waves are near 8.2 kilometers per second at depths between 40 and 100 kilometers, increasing slightly with greater depths. It is possible that the velocity decreases very slightly at some depths between 40 and 80 kilometers, but there is no sign of any discontinuity at depths between 40 and more than 500 kilometers. The $S$-waves seem to be affected a little more at depths between 40 and 100 kilometers than the $P$-waves. It is not impossible that at some depth between 40 and 80 kilometers there is a transition from the crystalline to the glassy state.

\section{REFERENCES}

1. WaDATI, K., "Shallow and Deep Earthquakes," Geophysical Magazine, 1, 162, 1928.

2. GutenberG, B., "Untersuchungen zur Frage, bis zu welcher Tiefe die Erde kristallin ist," Zeitschrift fïr Geophysik, 2, 24, 1926.

3. Jeffreys, H., "The Revision of Seismological Tables," Monthly Notices of the Royal Astronomical Society, Geophysical Supplement, 2, 329, 1931. 
4. Wood, H. O., and Rrchter, C. F., "A Study of Blasting Recorded in Southern California," Bulletin of the Seismological Society of America, 21, 28, 1931. "Recent Earthquakes Near Whittier, California,"-Bulletin of the Seismological Society of America, 21, 183, 1931.

5. GutenberG, B., "Travel Time at Small Distances, and Wave Velocities in Southern California," Gerlands Beiträge zur Geophysik, 1931. Not yet published.

6. Daty, R. A., "The Outer Shells of the Earth," American Journal of Science, 15, 108, 1928.

\section{Seismological Laboratory \\ Pasadena, California \\ March 1931}

